\title{
VI
}

\section{CAPITALISMO DEPENDENTE E A UNIVERSIDADE PÚBLICA BRASILEIRA: PARTICULARIDADES E DESAFIOS NO SÉCULO $\mathrm{XXI}^{*}$}

\author{
João Paulo Valdo
}

\section{INTRODUÇÃO}

"Universidades que, em vez de procurar melhorar o desempenho acadêmico, estiverem fazendo balbúrdia, terão verbas reduzidas". Essa frase do exministro da Educação, Abraham Weintraub (2019/2020), expressa a miséria do projeto hegemônico da política educacional brasileira. Não é um apelo à miséria como algo moralista. Assim como Minto (2014), acreditamos que a noção de miséria da política educacional brasileira

[...] representa o horizonte histórico dentro do qual a educação pode se realizar numa formação social sobre a qual a irradiação do MPC impõe limites estruturais, que não permitem o desenvolvimento de experiências educacionais autônomas e emancipadoras para as maiorias. Com isso busca-se reforçar seu sentido enquanto educação da particularidade brasileira, com funções adequadas a esta realidade e não a qualquer "modelo" de interação educação superior-sociedade abstraído de outras experiências históricas, ainda que estes possam ajudar a entender nossas especificidades (MINTO, 2014, p. 17).

Nossa proposta no presente capítulo é apresentar um conjunto de reflexões sobre a particularidade da formação e desenvolvimento da universidade pública brasileira e os desafios postos para a defesa da educação pública e gratuita na segunda década dos anos 2000. Para tal, o texto está estruturado em dois itens. Em um primeiro momento, recuperamos as análises apresentadas nos capítulos anteriores deste livro sobre a relação entre o padrão dependente de desenvolvimento e o padrão dependente de educação para fundamentar o exame das velhas/novas expressões da reconfiguração da universidade na atualidade. 
Em "Educação superior brasileira no século XXI" examinamos as alterações na política de educação superior e os ataques à universidade pública brasileira no século XXI, indicando a necessidade de enfrentamento e defesa do seu caráter público e de sua concepção como lócus de produção e socialização do conhecimento crítico.

\section{"UM MUSEU DE GRANDES NOVIDADES": A UNIVERSIDADE PÚBLICA BRASILEIRA NO CAPITALISMO DEPENDENTE}

Nosso ponto de partida expressa a relação dialética entre imperialismo e capitalismo dependente como eixo condutor fundamental para analisarmos a particularidade da formação da universidade brasileira. Destarte, partimos da compreensão que o capitalismo dependente faz parte do desenvolvimento do capitalismo em sua fase monopolista no Brasil, e:

[...] só pode ser apreendida na medida em que seu processo constitutivo - e indissociado da dinâmica dos capitalismos centrais - é apreendido nas suas especificidades históricas. Suas categorias, portanto, não serão "reelaboradas" a partir daquelas construídas na análise do capitalismo central, mas definidas em função de sua particularidade, isto é, da dinâmica histórica concreta em que estão inseridas, constituídas a partir das necessidades da expansão global do MPC (MINTO, 2014, p. 15).

A universidade, nesses termos, é parte desse processo, tanto na importação de modelos europeus de ensino e instituição, de uma escola superior feita pela elite para a elite, quanto na fase monopolista, onde o principal papel do ensino universitário é formar trabalhadores para universalizar o projeto burguês de sociabilidade às nações capitalistas dependentes, como afirma Florestan Fernandes (2005, p. 314).

O capitalismo monopolista não eclode nas economias periféricas rompendo o seu próprio caminho, como uma força interna irreprimível que destrói estruturas econômicas arcaicas ou simplesmente obsoletas, dimensionando e reciclando o que deveria ser preservado e forjando suas próprias estruturas econômicas ou extraeconômicas. Vindo de fora, ele se superpõe, como o super moderno ou o atual, ao que vinha antes, ou seja, o "moderno", o "antigo" e o "arcaico", aos quais nem sempre pode destruir e, com frequência, precisa conservar. O seu maior impacto construtivo consiste em cavar um nicho para si próprio, naquelas esferas das economias periféricas que são mais compatíveis com a transição, formando assim um exíguo espaço econômico, a partir do qual poderá cres- 
cer e quiçá irradiar-se para toda a economia, universalizando aos poucos os requisitos estruturais, funcionais e históricos inerentes ao seu próprio padrão de desenvolvimento capitalista.

Netto (2015), em diálogo com Florestan Fernandes, aponta que o desenvolvimento do capitalismo no Brasil não se construiu mediante o rompimento com o modelo arcaico de desenvolvimento, operou-se uma recomposição do atrasado elevando-o a funcionalidade hegemônica da classe dominante. Isso se construiu numa exclusão das forças populares nos processos de decisão política do país e o Estado teve papel funcional na condução e articulação des ses elementos apontados.

A característica do Estado brasileiro, muito própria desde 1930, não é que ele se sobreponha a ou impeça o desenvolvimento da sociedade civil: antes, consiste em que ele, sua expressão potenciada e condensada (ou, se quiser, seu resumo), tem conseguido atuar com sucesso como um vetor de desestruturação, seja pela incorporação desfiguradora, seja pela repressão, das agências da sociedade que expressam os interesses das classes subalternas. O que é pertinente, no caso brasileiro, não é um Estado que se descola de uma sociedade civil "gelatinosa", amorfa, submetendoa a uma opressão contínua; é-o um Estado que historicamente serviu de eficiente instrumento contra a emersão, na sociedade civil, das agências portadoras de vontades coletivas e projetos societários alternativos (NETTO, 2015, p. 34).

Um importante eixo condutor, bem explicitado por Fernandes (2005), demonstra que a combinação do processo de transformações capitalistas e dominação burguesa no Brasil é fruto da dupla articulação entre desenvolvimento desigual interno e dominação imperialista que se expressam a partir: i) da pressão do imperialismo sobre as nações dependentes, um padrão dual de apropriação do excedente econômico, a partir de dentro (burguesia nacional) e de fora (burguesia das nações do capitalismo central); e ii) da extrema concentração de riqueza, da drenagem para fora de maior parte do excedente econômico, configurando o caráter particular da exploração da força de trabalho nos países de economia dependente e exclusão dos trabalhadores das arenas de decisão política.

Esses elementos evidenciam a direção política das bases de formação da universidade no Brasil, conforme analisado anteriormente neste livro, especialmente nos capítulos 4 e 5. Para Fernandes (1975), o padrão de escola superior brasileiro, constituído no século XIX, nasce com limitações estruturais e funcionais, visto que a dependência cultural brasileira manteve uma escola superior 
com a tarefa primordial de garantir a transplantação de conhecimento produzido nos países centrais. A ruptura com a heteronomia educacional ocorreria a partir da desagregação do regimento colonial e da formação do regime de classes articulada ao rompimento com a dependência econômica e cultural com o exterior. Entretanto, tal fato não se efetivou.

A expansão do regime de classes sociais não impactou substancialmente no padrão de educação, pelo contrário, a nova etapa de desenvolvimento do ensino superior foi marcada por alterações quantitativas. A multiplicação das escolas superiores revitalizou o antigo padrão de ensino superior (articulação entre o arcaico e o moderno), formando uma conglomeração de escolas superiores isoladas que fortalecia a estrutura tradicional. Essa forma de organização da educação superior passou a ser considerada universidade (FERNANDES, 1975).

A escola superior tradicional e a universidade conglomerada são produtos de uma sociedade que se adaptou, estrutural e historicamente, a uma situação de dependência cultural imposta de fora para dentro. Os interesses e os valores sociais que orientaram o apontado crescimento institucional do ensino superior nasciam dessa situação de dependência educacional e cultural. Portanto, nem a escola superior tradicional nem a universidade conglomerada tinham forças para romper o imobilismo e as limitações dinâmicas do meio. Nasceram, ao contrário, para se adaptarem às exigências educacionais e culturais que as tornavam uma realidade histórica, como "má escola" e "universidade-problema" (FERNANDES, 1975, p.104).

O padrão de educação que se constituiu nas contradições da realidade brasileira formou uma universidade atravessada por problemas institucionais e sociais. Minto (2014), também em diálogo com a obra de Florestan Fernandes, menciona que o surgimento da universidade, sobretudo nos anos de 1930, expressou dois importantes aspectos na relação desenvolvimento capitalista e educação superior brasileira.

1) sob as condições da particularidade, a universidade não poderia alterar a lógica do desenvolvimento heterônomo. Daí o sentido "elitista", fragmentário e pouco integrado, que a universidade adquire ainda enquanto projeto, ao passo que a reação conservadora das classes dominantes brasileiras procurou eliminar do cenário político nacional os projetos então "alternativos", por que associados à perspectiva de um desenvolvimento nacional autônomo, para além da lógica do capitalismo dependente; 2) esse surgimento não ocorre sem contradições e são elas que vão definir a complexidade desse processo. A própria existência de projetos alternati- 
vos é uma prova disso, bem como a reação conservadora que mobilizaram contra si (MINTO, 2014, p. 173).

Fernandes (1975) aponta duas questões importantes sobre a reforma universitária nas primeiras décadas do século XX, quais sejam: em primeiro lugar, uma crítica a organização institucional da universidade que cumpria de maneira limitada a função de ensinar, sem atender às demandas nascentes de uma sociedade em transformação. Por isso, a necessidade de uma reforma no âmbito institucional para reorganizar a universidade (compreendendo a ampliação do seu conceito), a partir das modificações da realidade, na qual envolvia sua relação com a sociedade e demais instituições, a diversidade no ensino, na pesquisa e na construção do pensamento crítico.

Em segundo lugar, o movimento em disputa pela direção da reforma universitária, trouxe à tona as fissuras sociais e as resistências da cátedra conservadora e da classe dominante às mudanças na política educacional do país. Isso elevou as tensões para uma disputa no cenário mais amplo da sociedade, resultando na absorção parcial (daquilo que interessa a elite) das críticas radicais e reformistas, mas sem ferir as estruturas arcaicas da universidade. Entretanto, o crescimento e a consolidação da sociedade de classes em constante transformação, sobretudo no setor urbano industrial, tencionava a construção da nova universidade que saísse do imobilismo catedrático conservador (FERNANDES, 1975).

Havia, nesses termos, a possibilidade histórica de construção de uma universidade que acompanhasse as transformações e o desenvolvimento da realidade urbana do Brasil e a expectativa de um ambiente universitário com pensamento crítico que rompesse com a heteronomia cultural e a tutela externa, para produção de conhecimento, ciência e tecnologia de maneira autônoma e que preservasse a soberania nacional.

A reconstrução da universidade, deste ângulo, significa substituição de concepções, valores e estruturas autoritários e oligárquicos por concepções, valores e estruturas democráticos e igualitários. Foi por isso que o movimento de reforma universitária entrou em choque frontal com o pensamento e com o comportamento conservadores. Ele tinha de impor-se a negação, a destruição e a superação da ordem social existente, na medida em que não pode orientar-se de outro modo, sem sacrificar suas aspirações e seus objetivos mais caros e profundos. Acomodar-se às pressões e às composições conservadoras seria o mesmo que trair-se, relegando ou pervertendo os ideais democráticos que dão sentido à sua 
existência e legitimidade ao seu impacto revolucionário (FERNANDES, 1975, p.171).

A propósito de síntese, Minto (2014), aponta que as soluções apresentadas aos problemas da educação na ditadura deveriam dar conta de quatro questões essenciais e dialeticamente relacionadas, que seriam: 1) Aumento da demanda e expansão do nível superior, fruto do crescimento da urbanização e industrialização e das reivindicações da pequena burguesia e de setores da classe trabalhadora à educação superior; 2) Institucionalização de espaços para produção de pesquisa e tecnologia para incorporação aos novos padrões de desenvolvimento do grande capital; 3) educação superior como setor estratégico e 4) alterar a estrutura de um ensino ainda conectado as escolas isoladas e universidade conglomeradas.

Para Netto (2015), o enquadramento do sistema educacional brasileiro é derivado das mudanças estruturais que acarretavam demanda social por educação e como isso impactou em efeito político e social ameaçador da política educacional gestada pela ditadura.

Minto (2014) sinaliza duas características fundamentais na direção da reforma da educação superior conduzida pelo governo ditatorial. A primeira característica expressa uma política educacional que impediu a construção de uma universidade a partir das necessidades do país, reduzindo a educação superior numa lógica tecnicista pautada num conjunto de ações que propõe uma gestão independente em relação ao Estado, abrindo caminho para desresponsabilização do financiamento público para educação pública; diversificação do financiamento, pautada na escassez de recurso público e na busca de financiamento no setor privado; influência da teoria do capital humano ${ }^{1}$ na formação dos currículos; e regime de trabalho docente e administrativo baseado na produtividade e redução de custos.

A segunda característica trata do controle e repressão aos movimentos sociais que, na universidade, poderiam efetivar ações políticas contra o regime ditatorial e abrir possibilidade de construção de um projeto de universidade contra hegemônico.

Netto (2015) ressalta que a lógica educacional na ditadura foi refuncionalizada para atender os privilégios do grande capital e oferecer um novo direcionamento ao financiamento da política educacional, que passou a conviver com a lógica empresarial.

\footnotetext{
${ }^{1}$ Sobre a tese da teoria do capital humano ver Frigotto (2010).
} 
A privatização da educação superior foi uma política deliberada e conduzida pelo Estado ditatorial que implementou uma lógica tecnocrática as instituições estatais, reduzindo o financiamento público para as universidades públicas, e por consequência, a redução da educação ao ensino, deslocado da pesquisa e da produção do conhecimento, promovendo a ascensão do setor privado, um processo identificado por Florestan Fernandes (1975) como "privatismo exaltado". Essa participação é fundamental pelo fato do ensino superior privado - embora tenha suporte financeiro do Estado -, ter o papel de rebaixar a qualidade da formação, reduzir custo de operação e aumentar a taxa de lucro (MINTO, 2014).

Tal processo significa que a lógica privatista da educação superior no capitalismo dependente foi parte da modernização conservadora do Brasil e sua adequação aos novos padrões e estágio do capitalismo monopolista.

Como processo real de reprodução da educação no interior das condições do desenvolvimento capitalista, possui interesses econômicos claros, mas que concretizam por meio de disputas políticas e ideológicas entre forças sociais concretas. O ensino superior privado não era insignificante em termos quantitativos, mas adquiriu um novo significado, de modo algum restrito à orientação jurídico-formal. Trata-se de um sentido amplo: privatizar passou a denotar a organização e reorganização permanente do nível superior de ensino nas condições do novo padrão de acumulação capitalista pós-crise dos anos 1960/1970 (MINTO, 2014, p. 261).

Por outro lado, precisamos levar em consideração que o processo de neutralização conduzido pela política educacional na ditadura não minou os setores da população inconformados com essa lógica.

Esta afirmação não deve ser tomada como denotando o enquadramento, o controle e a manipulação plenos do sistema educacional pela ditadura. Este limite só seria alcançável se a autocracia burguesa obtivesse a inteira equalização do sistema erradicando os vetores contraditórios (endógenos e exógenos) nele operantes. A isso não chegou a política educacional do Estado ditatorial: Ela repôs, num piso mais alto e de maior complexidade, todos os dilemas históricos da educação institucional no Brasil. Permaneceram as fraturas; contradições - mesmo asfixiadas - não foram superadas; logo que a resistência democrática e o movimento popular retomaram a ofensiva na segunda metade da década de 1970, a dinâmica represada no/do sistema educacional ressurgiu abertamente. Mas ainda: a política educacional da ditadura não impediu nunca que a resistência democrática conservasse áreas sob a sua influência, mesmo que extrema- 
mente restritas, nem jamais obteve sucesso no seu esforço para conquistar nesse terreno, um patamar mínimo de legitimação e consenso ativo (NETTO, 2015, p. 90).

O aprofundamento da heteronomia cultural na educação no contexto de autocracia burguesa durante os anos de ditadura civil-militar impulsionou novamente a luta de classes como elemento fundamental para o rompimento do modelo burguês de dominação e a abertura para o processo de redemocratização e de construção de outra política educacional. A resistência democrática, mesmo que pequena, no interior das universidades brasileiras abriu caminho para o movimento político da classe trabalhadora na luta pela redemocratização e de participação ampliada nos espaços políticos e sociais do país (LEHER, 2018).

A quadra histórica que se abre no Brasil nos meados dos anos 1970 ao início dos anos 1980, com o processo de desgaste e crise do regime ditatorial, a reorganização da classe trabalhadora, articulado aos impactos da crise econômica internacional, elevaram a sociedade brasileira a um processo de transição política e econômica, que debateremos no item a seguir.

\section{EDUCAÇÃO SUPERIOR BRASILEIRA NO SÉCULO XXI}

As mudanças no mundo da produção com as inovações tecnológicas e a mundialização financeira impuseram novas condições para produção e reprodução das relações sociais. O período histórico de 1960 a 1980 marcou a emersão e consolidação de uma nova crise do capitalismo, ancorado no desgaste no Estado de Bem Estar Social e no padrão fordista de produção capitalista, e a necessidade da reestruturação produtiva para alcançar novos patamares de exploração da força de trabalho e acumulação de capital.

O contexto desfavorável ao imperialismo aponta duas frentes de reação burguesa, nesse período. A primeira, o ataque à classe trabalhadora no esfacelamento do Estado de Bem Estar Social, atribuindo aos direitos sociais dos trabalhadores a origem da crise. A segunda reação burguesa será expressa nas alterações no processo produtivo fordista e na instauração do processo de acumulação flexível, que dará base à reestruturação do capitalismo no seu estágio mais contemporâneo (NETTO; BRAZ, 2011).

Em relação ao processo de produção (mas não se limitando a ele), a acumulação flexível, além de confrontar a rigidez do fordismo, eleva a produção e reprodução das relações sociais burguesas ao um novo patamar de desen- 
volvimento. Um processo de flexibilização das relações sociais de produção de reprodução de capital.

A acumulação flexível envolve rápidas mudanças dos padrões do desenvolvimento desigual, tanto entre setores como entre regiões geográficas, criando, por exemplo, um vasto movimento no emprego no chamado "setor de serviços", bem como conjuntos industriais completamente novos em regiões até então subdesenvolvidas [...] (HARVEY, 2000, p. 140).

A reestruturação produtiva, com base no processo de acumulação flexível, é incorporada por intensos processos de avanços tecnológicos que altera todo o processo produtivo e reduz a demanda por trabalho vivo. De um lado, embora com a produção em grande escala, a produção se volta a nichos de mercados específicos e diversificados. De outro a desterritorialização da produção, deslocando as indústrias para novos espaços com menor custo de força de trabalho (NETTO; BRAZ, 2011).

A reação burguesa para a retomada de crescimento e dominação, frente à crise dos anos 1970, tem sua expressão no que ficou denominado como projeto neoliberal, que operou em diversas frentes como: a desregulamentação dos mercados financeiros; a flexibilização das relações e dos processos de trabalho, através da reestruturação produtiva; e alteração/redução no papel do Estado a setores estratégicos; e a privatização dos setores públicos.

O processo de emergência e consolidação do projeto neoliberal no Brasil carrega traços de particularidades articulados ao contexto internacional, já que um importante argumento desse texto, em sua interlocução com a obra florestaniana, é, exatamente, a dialética imperialismo - capitalismo dependente. A ofensiva neoliberal brasileira também é conduzida pela flexibilização das relações de trabalho, desregulamentação do mercado e reestruturação do Estado e privatização do setor público, com centralidade no último, como bem apontam Behring e Boschetti (2011):

[...] argumentava-se que o problema estaria localizado no Estado, e por isso seria necessário reformá-lo para novas requisições, corrigindo distorções e reduzindo custos, enquanto a política econômica corroia aceleradamente os meios de financiamento do Estado brasileiro através de uma inserção na ordem internacional que deixou o país à mercê dos especuladores no mercado financeiro, de forma que todo o esforço de redução de custos preconizado escoou pelo ralo do crescimento galopante das dívidas internas e externas (BEHRING; BOSCHET'TI, 2011, p. 152). 
Essas reações da burguesia em sua dupla face (nacional e internacional) têm como objetivo criar condições políticas, econômicas e sociais para a construção do novo padrão de acumulação e, nesse contexto, a contrarreforma do Estado foi um elemento central da reação burguesa para retomada da sua dominação. É nesse bojo também que foi conduzida a contrarreforma da educação (LIMA, 2005).

Os anos de 1990 demarcam a ofensiva do projeto neoliberal no país pela implementação dos direcionamentos do consenso de Washington. As direções recomendadas pelo Banco Mundial para ajuste na periferia do capital como redução no gasto público, desregulamentação dos mercados e das instituições públicas, contrarreforma do Estado e privatização de áreas estratégicas da economia nacional, como argumento para retomada de crescimento econômico, foram adotadas e seguidas pelos governos brasileiros nesse período (de Collor a FHC).Para Lima (2005), as

[...] reformas educacionais, elaboradas, difundidas pelos organismos internacionais, são expressões das condicionalidades impostas no processo de ajuste estrutural aos países periféricos e têm como objetivos: (1) configurar um novo projeto de sociabilidade burguesa que naturalize o processo de mercantilização da totalidade da vida social e (2) viabilizar o movimento mais amplo do capital em crise em busca de novos mercados e novos campos de exploração lucrativa, a partir da perversa lógica de empresariamento da educação (LIMA, 2005, p. 89).

Outro importante elemento teórico/político a ser ressaltado foram os embates classistas antagônicos em torno do PNE 2001 - 2011 (Lei n $^{\circ}$ 10.172/2001) e o PNE - Proposta da Sociedade Brasileira. O primeiro apresentado pelo governo FHC que, em linhas gerais, defendia o projeto privatista para política educacional no Brasil. O segundo foi construído pelos movimentos sociais e entidades científicas em defesa da educação pública brasileira. O PNE da Sociedade Brasileira defendia o financiamento público para universidade pública, a indissociabilidade entre ensino, pesquisa e extensão; uma formação voltada para uma sociedade mais justa e que atenda as demandas e necessidades da população e a defesa da autonomia universitária. Esses embates entre projetos antagônicos constituíram um importante marco nas lutas sociais em defesa da educação do período, no entanto, não impediram as constantes ofensivas do capital à educação pública. A conjuntura que se abre no século XXI é de desafios à luta por uma educação pública, democrática e classista. 
O receituário da ofensiva neoliberal brasileira, na entrada do novo século, é permeado, portanto, por inúmeras tensões na luta das classes sociais, sobretudo, em consequência da insatisfação popular com os ajustes estruturais. Uma nova fase da contrarrevolução neoliberal (LIMA, 2005) impacta as relações sociais do país e exige a reação burguesa para manutenção de sua dominação e hegemonia.

Para Castelo (2012), ao perceber os desgastes iniciais do neoliberalismo operou-se uma dupla movimentação na realidade latino-americana, qual seja: i) promoção de políticas sociais focalizadas nas expressões mais profundas da "questão social", naquilo que foi denominado social liberalismo, que possibilitou um novo fôlego para classe dominante; e ii) levante da classe trabalhadora em oposição as políticas de ajustes estruturais do projeto neoliberal.

Ao longo dos anos 1990 e início do novo século a política educacional, particularmente a educação superior, passa (principalmente a partir do reordenamento do papel do Estado), por um intenso processo deprivatização que se expressa pelas estratégias de diversificação das instituições de ensino superior e das fontes de financiamento norteadas pelas orientações dos organismos internacionais do capital.

Compete à educação operar as contradições da segregação, propiciando aberturas para o futuro. O pressuposto, aqui presente, é: todos aqueles que fizerem as escolhas educacionais corretas terão possibilidades ilimitadas. Os indivíduos (e países) que priorizarem corretamente a educação terão um futuro radioso pela frente, comprovando, deste modo, a validade das bases do sistema. O capitalismo atual é justo com aqueles que souberem se qualificar corretamente. Basta não insistir nas prioridades erradas. Não adianta gastar com o ensino superior e a pesquisa, pois, conforme a tese das vantagens comparativas, os países em desenvolvimento devem perseguir nichos de mercado onde seja possível vender mercadorias de baixo valor agregado (LEHER, 1999, p. 29).

Segundo Cislaghi (2012) o primeiro período de mudanças neoliberais na política educacional direcionada pelo Banco Mundial ocorreu a partir 1994 até o fim da década de 1990, tinha como objetivo o desmonte da educação superior via arcabouços jurídicos e incentivos ao setor privado. $\mathrm{Na}$ virada para os anos 2000, a contrarreforma ganha novos contornos e a necessidade de legitimar um novo modelo que vinha sendo implementado por meio da diversificação em várias frentes. Nessa direção, a autora menciona que,

O documento do Banco Mundial de 2003, "Construir sociedades de conhecimentos: novos desafios para a educação terciária”, também relacio- 
na os objetivos almejados do ensino terciário às propostas gerais para o desenvolvimento fixadas pelo Banco. Nesse contexto, o ensino terciário teria entre seus objetivos a redução da pobreza, através do aumento da produtividade dos países capacitando a força de trabalho local, gerando novos conhecimentos e adaptando conhecimentos globais ao uso local, além de aumentar as oportunidades de emprego e ascensão para estudantes com menos recurso. Ou seja, fica claro o duplo objetivo: formar força de trabalho qualificada de acordo com as necessidades do modelo de acumulação e ao mesmo tempo buscar coesão social, ampliando as possibilidades de acesso ao ensino superior, mesmo que menos qualificadas (CISLAGHI, 2012, p. 268).

Essas tendências externas ao Brasil que orientaram (e orientam) a construção da política educacional, bem como a política econômica, na entrada do novo século são marcadas por novas configurações da luta de classes e a disputa de projetos antagônicos para educação pública e sociedade, que tiveram seu ápice na eleição presidencial de Luís Inácio Lula da Silva.

Para Lima (2007) a "Coligação Lula Presidente" não representou a vitória da classe trabalhadora e uma ruptura com as políticas neoliberais, pelo contrário, o PT apresentou uma política de transformação do partido a ordem burguesa, com um projeto que possuía diretrizes afinadas aos pressupostos teóricos do social liberalismo, que se expressaram na construção de uma agenda possível de humanização do capitalismo.

Ao avaliar o governo Lula (2003 - 2010), Leher (2010), menciona que as alianças construídas pelo transformismo do PT, contaram com a direção de setores da burguesia, que conduziram uma política educacional nos marcos do governo Cardoso, vide as medidas jurídicas política, como por exemplo, o PNE 2001-2010.

O processo de contrarreforma da educação superior nos governos Lula contou com amplo arcabouço jurídico político, que legitimou as diretrizes presentes no Plano Diretor da Reforma do Estado/PDRE e no Plano Nacional de Educação/PNE (2001-2011), como as parcerias público-privadas, sob o discurso de ampliação e democratização do acesso ao ensino superior no Brasil, merecendo destaque dentre elas: a instituição do Programa Universidade para Todos (ProUni) através da lei n ${ }^{\circ} 11.096 / 2005$; a lei de parceria público privada $n^{\circ}$ 11.079/04, que trata das diretrizes gerais da parceria público-privado na administração pública; os decretos 5622/05 e 5.800/06 que regulam o EaD e cria a Universidade Aberta do Brasil (UAB), respectivamente, para oferta de cursos à distância; o decreto $n^{\circ}$ 6.069/07 que cria o Programa de Apoio a Planos de Reestruturação e Expansão das Universidades Federais (REUNI); e a medida 
provisória 520/10 que autoriza a criação da Empresa Brasileira de Serviços Hospitalares (EBSERH), empresa pública de direito privado vinculada ao MEC.

Lima (2013) aponta que as ações que fundamentam a reestruturação da educação superior nos governos de Lula compõem um conjunto de medidas oriundas do processo de contrarreforma do Estado e expressa uma nova fase da expansão da política de educação superior que podem se caracterizadas em dois eixos. O primeiro eixo consiste na privatização e mercantilização da educação superior e se desdobra em três frentes: a) o aumento da IES privadas, principalmente focadas no ensino, e financiamento público ao setor privado através do Fundo de Financiamento Estudantil (FIES) e do ProUni; b) a privatização interna das universidade públicas através dos vendas de "serviços educacionais", como os cursos pagos, fundações de direito privado, a lei de inovação tecnológicas e a lei de parceria público privadas.; e c) o produtivismo que atravessa a política de pesquisa a pós graduação via CAPES e CNPq (LIMA, 2013).

A certificação em larga escala ou massificação da formação, segundo Lima (2013), caracteriza o segundo eixo e pode ser identificada nas políticas de expansão como Ensino a Distância/EaD, REUNI e ProUni, causando intensificação no trabalho docente e a reconfiguração, principalmente, da universidade pública, visto que o REUNI impôs uma lógica de expansão centrada no ensino, fragmentando o tripé universitário de ensino, pesquisa e extensão.

As análises do conjunto de medidas da contrarreforma dos dois mandatos presidenciais do Lula (2003-2010) demonstram que o processo de expansão da educação superior manteve sua maior inclinação ao setor privado, representando a concretização da condução de um projeto educacional que carrega traços fundamentais da política educacional brasileira: a privatização, a heteronomia e a massificação, a serviço das necessidades do capitalismo dependente.

A conjuntura que se abre aos governos do PT com a liderança de Dilma Rousseff (2011-2016), ainda que com a continuidade dos governos Lula, foi marcada por tensões políticas e econômicas que esgotam, de maneira drástica, o ciclo petista. As análises de Sampaio Jr. (2017) indicam que a crise economia mundial iniciada em meados de 2007 foi aprofundada em 2008 em decorrência do colapso da especulação imobiliária norte americana e pela quebra em cadeia de bancos que aparentavam ser inabaláveis. Entretanto, o recrudescimento da crise a partir de 2011 e o esgarçamento das ações anticíclicas com base na elevação de gastos públicos, com socorro econômico e financeiro aos grandes grupos econômicos internacionais, na tentativa de controlar o desmoronamento do 
mercado, demonstraram que a economia mundial não constrói ação reguladora perante a anarquia da iniciativa privada, imersa no processo de desregulamentação e liberalização dos mercados financeiros (SAMPAIO JR., 2017).

Esses elementos atestam os fatos e mitos que sustentaram a falácia neodesenvolvimentista do PT durante o período que estivem a frente do planalto. Muito porque se construiu um discurso de que o Brasil vivenciava um processo de desenvolvimento que possibilitaria a superação da pobreza e da dependência externa, ignorando o fato de que o frágil ciclo expansivo do período petista reforçou o eixo condutor da particularidade do capitalismo monopolista brasileiro, que é a dupla articulação entre o desenvolvimento desigual interno e a subordinação consentida ao capital internacional (SAMPAIO JR., 2017). Tais elementos políticos são identificados na conversão dos governos de Lula da Silva e Dilma Rousseff, assim como os anteriores, em defesa da política compensatória do Banco Mundial e dos ajustes fiscais permanentes que demarcaram uma política econômica nacional que gasta mais com o pagamento da dívida pública do que com direitos sociais.

A mudança do cenário econômico mundial, interessantemente não a crise propriamente dita, mas a retomada do crescimento no centro do sistema e o consequente agravamento da crise da periferia do sistema do capital imperialista, faz com que as bases da democracia de cooptação e do governo de pacto social deterioram rapidamente. O primeiro e mais evidente sintoma desse fato foram às manifestações de 2013, que indicavam problemas em um dos principais trunfos do PT na relação com a ordem burguesa, ou seja, a eficiência do apassivamento (IASI, 2017, p. 427).

Entre o período de 2012 e 2014, durante os governos de Dilma Rousseff, sob os desgastes da crise econômica mundial, a insatisfação da população com desperdício de recurso público em projetos faraônicos dos megaeventos esportivos, colocou em decadência a euforia neodesenvolvimentista e a ideia de que o Brasil superaria o subdesenvolvimento, evidenciando um cenário de que voltaríamos a viver um período de estagnação política e econômica no país. Ademais, sem ter confrontado e resolvidos os fundamentos dos problemas do povo e a opção de enfrentar a crise com ajuste neoliberal de receituário ortodoxo, comprometeu não só o segundo mandato de Dilma, como encaminhou o desfecho decadente e melancólico do ciclo petista (SAMPAIO JR., 2017).

No que se refere a política educacional, a principal ação do governo de Dilma foia construção do novo Plano Nacional de Educação (2014- 2024), que tem como principal tarefa legitimar as ações do PT ao longo dos seus governos 
e da política educacional privatista, inclusive recuperando elementos e metas do último PNE que teve vigência até 2011, e fora construído no governo FHC. Mais um elemento que evidência a solidez do projeto educacional hegemônico da burguesia brasileira que, embora com diferença entres os últimos governos, atravessa e direciona a política de educação do país, especialmente a educação superior.

Para Minto (2018) quando na elaboração do novo PNE, as ações que envolvem principalmente a previsão de ampliação de recurso orçamentário e responsabilização do Estado no financiamento dão concretude à política educacional. O autor (2018) considera que a disputa na construção do PNE abriu as possibilidades de alteração das diretrizes da política de educação superior e que, para o setor privado foi um momento estratégico de reorganizar seus interesses junto ao Estado para elaboração de novas formas de captura do fundo público.

A consequência desse processo foi o fortalecimento econômico e político das IES privadas, sobretudo, seus grupos econômicos, com forte presença no capital internacional, que passam a comprar IES de pequeno porte, provocando ao setor privado um crescente processo de internacionalização e centralização de capitais (DRUCK; FILGUEIRA; MOREIRA, 2017).

No complexo movimento de expansão do ensino superior privado, observam-se dois processos que caracterizam a reestruturação capitalista: de concentração das atividades em grandes grupos empresariais - que, entre outras coisas, compram as IES menores; e de diversificação das atividades, atrelando-se ao capital financeiro internacional e tendo nas atividades de ensino (e, cada vez mais, na pesquisa) apenas meios para realização de lucros (MINTO, 2018, p.15).

Para Lima (2017) o período que marca os governos do PT (2003- a 2016) representou, inicialmente: um processo histórico de aburguesamento da política petista que substituiu na sua pauta de ação política a revolução contra a ordem, pela ocupação do poder, via acordo pelo alto, sustentando pela coalização de classe e que operou uma política que privilegiou o pagamento e amortização da dívida externa, num permanente processo de tributo colonial da dívida pública. No entanto, o caráter ultraconservador da burguesia brasileira impôs limites ao pacto de classe e demonstrou que em contexto de crise do capital, não há possibilidade de atender as demandas da classe trabalhadora.

É nesse caminho que, segundo Iasi (2017), o governo golpista e usurpador de M. Temer teve início. Um governo descartável que representou uma "ponte para o futuro" e não o futuro. Sua tarefa foi impor um ajuste estrutural, 
aprofundando as medidas do grande capital que podem ser identificadas em três frentes: ajuste econômico, medidas de caráter ideológico e medidas jurídico políticas. Outro importante elemento que marcou continuidades e descontinuidades entre o PT e M. Temer foi o estudo encomendo ao Banco Mundial, ainda no segundo governo Dilma Rousseff. Um material previamente destinado para justificar os ajustes em curso no Brasil, intitulado: "Um Ajuste Justo: Análise da Eficiência e Equidade do Gasto Público no Brasil". O documento "caiu como uma luva" ao governo Temer que já vinha operando medidas de austeridades como o congelamento das despesas públicas por 20 anos, a liberação da terceirização para qualquer setor da atividade das empresas e uma reforma trabalhista que retrocede os direitos da classe trabalhadora (DRUCK; FILGUEIRA; MOREIRA, 2017).

Esse documento representou a principal ação do Governo Temer também direcionada para a política educacional. As diretrizes direcionadas a educação superior recuperam os documentos anteriores e apresentam as seguintes orientações e medidas para as universidades públicas: redução dos recursos destinados; introdução do ensino pago; financiamento aos estudantes que não puderam pagar as mensalidades, aos moldes do FIES; e bolsa de estudos aos estudantes mais pobres, via PROUNI (DRUCK; FILGUEIRA; MOREIRA, 2017).

Outra importante reflexão deve considerar as disputas entre os projetos antagônicos da política educacional, principalmente no século XXI, que se expressam na elaboração e aprovação do PNE 2001-2011 e 2014-2024 representando a política educacional hegemônica, de um lado e de outro, na construção dos movimentos sociais do PNE da Sociedade Brasileira, e nos documentos da CONEDEP/ENE de 2014 e 2016.

As resistências e lutas em prol da educação pública, nas últimas décadas do século passado e no início do século XXI, sobretudo em torno do FNDEP e do CONED, para Leher (2018), expressaram um importante saldo organizativo dos movimentos sindicais e estudantis em relação a construção de ações políticas contra a agenda neoliberal, principalmente na construção coletiva em torno do PNE da sociedade brasileira, que representou um projeto educacional antagônico a LDB (1996) e o PNE (2001 - 2011) aprovados no governo de FHC.

Leher (2018) aponta que nos anos 2000 as correlações de forças nas lutas sociais são marcadas pela desorganização da classe trabalhadora, sobretudo, com a política de conciliação conduzida pelo PT que resultou em diversas medidas ecléticas do campo educacional, favorecendo a agenda do capital, como por exemplo, a aprovação do PNE 2014-2024. 
Podemos considerar que o período dos governos do PT foi marcado pela subordinação a lógica do capital no âmbito da educação e, também, por inúmeras resistências da classe trabalhadora, que construíram iniciativas de reorganização das lutas, com diversas greves, paralisações e jornadas de lutas em defesa da educação pública e contrárias a política educacional do PT, com forte liderança dos movimentos sindical e estudantil (ABEPSS, ANDES/SN, CSP Conlutas, CFESS, FASUBRA, SINASEFE, ANEL, Executivas de cursos, OE da UNE, dentre outras).

Consubstanciado nessas reflexões, concordamos com Leher (2018), que a construção do Encontro Nacional de Educação, a partir de 2014, marca um novo ponto de partida para as lutas educacionais, que obviamente recupera todos os saldos organizativos e lições históricas da organização dos movimentos sociais da educação.

$\mathrm{O} \mathrm{ENE}^{2}$ expressou (e expressa) um importante marco da reorganização dos movimentos sociais da educação na construção de um projeto classista e democrático para educação. Um contexto marcado pelo impacto da política de pacto de classe e democracia de cooptação, conduzida pelo PT, na organização da classe e sua política educacional afinado com os organismos internacionais do grande capital, consolidando sua guinada a partido da ordem e acirrou as contradições no campo das lutas da esquerda, provocando rachas em diversas entidades e instância do movimento, e apontou a necessidade histórica de uma alternativa política classista, autônoma e independente, que atendesse as necessidades da classe trabalhadora. Portanto, foi nessa direção que diversas entidades e movimentos sociais vêm construindo desde 2014 o ENE e, por isso, esse espaço representa um novo ponto de partida.

\section{CONSIDERAÇÕES FINAIS}

A proposta desse capítulo foi, em diálogo com a obra florestaniana, apresentar um conjunto de reflexões sobre a particularidade da formação e desenvolvimento da universidade pública do Brasil e sinalizar as disputas em torno de projetos antagônicos da educação, expressos pelas ações do Estado e burguesia versus movimentos sociais em defesa do projeto classista e democrática da educação.

Minto (2018) aponta três dimensões da contrarreforma na política educacional brasileira. Primeira é a educação superior como sistema, que abrange o

\footnotetext{
${ }^{2}$ Que hoje é construído no âmbito da CONEDEP - Coordenação Nacional das Entidades em Defesa da Educação Pública, e realizou sua última edição em 2019, em Brasília, na UnB.
} 
plano mais geral e as relações entre educação, Estado e sociedade, que se manifestam no contexto das transformações do capitalismo e os impactos na política educacional. O segundo é o institucional, que articulado com a primeira, opera mudanças no processo de reorganização das instituições. Última, em articulação com as demais, diz respeito aos impactos diretos das contrarreformas no cotidiano das IES públicas e privadas, seja na força de trabalho ou na pesquisa, ensino e extensão (MINTO, 2014).

A conjuntura que se abre com o governo Bolsonaro e sua proposta para educação superior, expressa no "Future-se", nos colocam desafios para luta política em defesa da universidade pública. Lima (2019) aponta que está em movimento uma nova fase da contrarreforma do Estado e da educação superior, via contrarrevolução preventiva, que se opera em dois ofensivos movimentos: a intensificação e aprofundamento da mercantilizaçãoda política educacional superior; e a perseguição a professores e estudantes na construção do pensamento crítico e na ameaça a organização políticas desses segmentos.

O projeto Future-se é o "Fature-se" das Instituições de Ensino Superior Pública dos pais, à venda direta e irrestrita da educação superior pública, é um salto ao passado colonial (FILHO; FARAGE, 2019). Nossa tarefa frente à ofensiva de ultradireita e conservadora a educação superior são: a) identificá-lo nos marcos da relação dialética entre imperialismo e capitalismo dependente que aponta o eixo condutor do projeto hegemônico da educação brasileira, qual seja: privatista e tutelado pelo exterior de forma consentida; e b) luta e resistência como ponto imperativo na (re)construção e (re)organização das nossas bases em direção da construção do projeto classista e democrático para educação brasileira, em consonância com as reflexões e as ações políticas do saudoso intelectual militante Florestan Fernandes.

\section{REFERÊNCIAS}

BEHRING, E. R.; BOSCHETTI, I. Política Social: fundamentos e história. 9. ed. São Paulo: Cortez, 2011.

BRASIL. Presidência da República. Casa Civil. Lei no 11.079, 30 de dezembro de 2004. Institui normas gerais para licitação e contratação e parceria públicoprivada no âmbito da administração pública. Diário Oficial da União, Brasília, DF, 2004. 
. Ministério da Educação. Lei no 11.096, 13 de janeiro de 2005. Institui o Programa Universidade para Todos - PROUNI, regula a atuação de entidades beneficentes de assistência social no ensino superior; altera a Lei $\mathrm{n}^{\circ} 10.891$. de 9 de julho de 2004, e dá outras providências. Diário Oficial da União, Brasília, DF, 2005.

. Presidência da República. Casa Civil. Decreto no 5.622, 19 de dezembro de 2005. Regulamenta o art. 80 da Lei no 9.394, de 20 de dezembro de 1996, que estabelece as diretrizes e bases da educação nacional. Diário Oficial da União, Brasília, DF, 2005.

. Presidência da República. Casa Civil. Decreto nº 5.800 , de 8 de junho de 2006. Dispõe sobre o Sistema Universidade Aberta do Brasil - UAB. Diário Oficial da União, Brasília, DF, 2006.

. Presidência da República. Casa Civil. Decreto no 6.069, de 27 de março de 2007. Regulamenta a Gratificação de Desempenho de Atividades Especializadas e Técnicas de Informações e Avaliações Educacionais - GDIAE e a Gratificação de Desempenho de Atividades de Estudos, Pesquisas e Avaliações Educacionais - GDINEP de que trata o art. 62 da Lei no 11.357, de 19 de outubro de 2006. Diário Oficial da União, Brasília, DF, 2007.

CASTELO, R. O social-liberalismo brasileiro e a miséria ideológica da economia do bem-estar. In: MOTA, A.E. (Org.). Desenvolvimentismo e construção de hegemonia: crescimento econômico e reprodução da desigualdade. São Paulo: Cortez, 2012. p. 46- 77.

CISLAGHI, J. F. Financiamento do ensino superior no Brasil: novos contornos e antigos mecanismos de privatização do fundo público. In: SALVADOR, E.; BEHRING, E. R.; BOSCHETTI, I.; GRANEMANN, S. (Org.). Financeirização, fundo público e política social. São Paulo: Cortez, 2012. p. 261- 284.

DRUCK, G.; FILGUEIRAS, L.; MOREIRA, U. Ajuste fiscal e as universidades públicas brasileiras: a nova investida do banco mundial. Cadernos CEAS, Salvador, n. 242, p. 603- 634, set./dez. 2017. 
FERNANDES, F. Universidade brasileira: reforma ou revolução? São Paulo: Alfa-Omega Editores, 1975.

A revolução burguesa no Brasil: ensaio de interpretação sociológica. 5. ed. São Paulo: Globo, 2005.

FILHO, A. G.; FARAGE, E. Educação Superior Pública e o Future-se: o projeto do capital em tempos de ascensão da extrema direita. Em Pauta, Rio de Janeiro, n. 44, v. 17, p. 33-49, jul./dez. 2019.

FRIGOTTO, G. A produtividade da escola improdutiva: um (re)exame das relações entre educação e estrutura econômico-social capitalista. 9. ed. São Paulo: Cortez, 2010.

HARVEY, D. Condição pós-moderna. 9. ed. São Paulo: Loyola, 2000.

IAISI, M. Política, Estado e ideologia na trama conjuntural. São Paulo: ICP, 2017.

LEHER, R. Um novo senhor da educação? A política do Banco Mundial para a periferia do capitalismo. Revista Outubro, São Paulo, v. 1, n. 3, p. 19-30, 1999. Disponível em: < http://www.revistaoutubro.com.br/edicoes/03/ out3 03.pdf $>$.Acesso em: 19 ago. 2020 .

. Educação no Governo de Lula da Silva: a ruptura que não aconteceu. In: MAGALHAES, J. P. de A. (org.) et al. Os anos Lula: contribuições para um balanço crítico 2003- 2010. Rio de Janeiro: Garamond, 2010. p. 369- 412.

.Universidade e heteronomia cultural no capitalismo dependente. Um estudo a partir de Florestan Fernandes. Rio de Janeiro: Consequência, 2018.

LIMA, K. Reforma da educação superior nos anos de contra-revolução neoliberal: de Fernando Henrique Cardoso a Luiz Inácio Lula da Silva. 2005. 466 f. Tese (Doutorado em Educação) - Faculdade de Educação, Universidade Federal Fluminense, Niterói, 2005. 
Contra-reforma na educação superior: de FHC a Lula. São Paulo: Xamã, 2007.

- Expansão da educação superior brasileira na primeira década do novo século. In: PEREIRA, Larissa. Dahmer.; ALMEIDA, Ney. Luiz Teixeira. de (Org.). Serviço Social e educação. Rio de Janeiro: Lumens Juris, 2013, p. 11 34.

. Brasil em tempos de contrarrevolução. Universidade e Sociedade, Brasília, n. 59, p. 92- 103, jan./jun. 2017.

. Universidade pública e contrarrevolução: da "travessia de uma ponte" ao "caminho da prosperidade".Em Pauta, Rio de Janeiro, v.17, n. 44, p. 15-31, jul./dez. 2019.

MINTO, L. W. A educação da miséria. Particularidade capitalista e educação superior no Brasil. São Paulo: Outras Expressões, 2014.

. Educação superior no PNE (2014-2024): apontamentos sobre as relações público-privadas. Revista Brasileira de Educação, Rio de Janeiro, v. 23, p. 1-17, 2018.

NET'TO, J. P. Ditadura e Serviço Social. Uma análise do Serviço Social no Brasil pós-64. 17. ed. São Paulo: Cortez, 2015.

NET'TO, J. P.; BRAZ, M. Economia Política: uma introdução crítica. 7. ed. São Paulo: Cortez, 2011.

SAMPAIO JR., P. de A. Crônica de uma crise anunciada: crítica à economia política de Lula e Dilma. São Paulo: SG-Amarante, 2017. 